\title{
The Effects of Aging on Hepatic Microsomal Scaling Factor and Hepatocellularity Number in the Horse
}

Authors: Khaled A. Shibany ${ }^{\mathrm{a}, \mathrm{b}}$, Sabine Tötemeyer ${ }^{\mathrm{a}}$, Stefanie L. Pratt ${ }^{\mathrm{a}}$, Stuart W. Paine ${ }^{\mathrm{a}, *}$

Authors' affiliation:

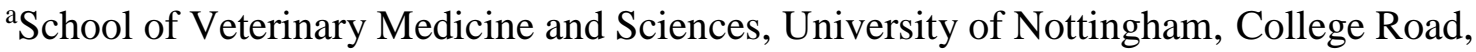

Sutton Bonington, Leicestershire, LE12 5RD, UK

${ }^{b}$ Departement of Internal Medicine, Faculty of Veterinary Medicine, University of Tripoli, Tripoli, Libya

*Corresponding author.

Phone +44 (0)115 9516615; FAX: +44 (0)115 951 6440;

E-mail address: stuart.paine@ nottingham.ac.uk 


\begin{abstract}
Scaling factor values for the in vitro-in vivo extrapolation of hepatic metabolic clearance for xenobiotics have not yet been determined in horses. Scaling factors were determined by comparing the total protein and or CYP P450 content in microsomes and cryopreserved hepatocytes against the content in the liver. Microsomal protein per gram of liver (MPPGL) and hepatocellularity number per gram of liver (HPGL) using CYP P450 content method ranged $41-73 \mathrm{mg} /$ gram of liver (mean= $57 \mathrm{mg} /$ gram of liver, $\mathrm{n}=39)$ and $146-320 \times 10^{6} \mathrm{cells} / \mathrm{g}$ of liver $\left(\right.$ mean $=227 \times 10^{6}$ cells $/ g$ of liver, $\left.n=18\right)$, respectively; and $156-352 \times 10^{6}$ cells $/ g$ of liver $\left(\right.$ mean $=232 \times 10^{6}$ cells/g of liver $)$ using total protein method. A non-monotonic and inverse relationship between age and MPPGL and HPGL, respectively, was observed. Between 1 and 20 years of age the liver cell size decreases as age increases. Subsequently, the cell size increases until the hepatocytes of the oldest horses approached the size found in the youngest horses. Hepatocyte density was inversely related to the size of the hepatocytes. This study provides the first extensive and comprehensive data demonstrating the relationship between the size of hepatocytes and HPGL in any species.
\end{abstract}

\title{
Keywords:
}

Aging

Hepatocellularity

Horse

Liver

Microsomal

Scaling factors 


\section{Introduction}

Hepatocytes and liver microsomes obtained from several species including human are routinely used to determine the intrinsic clearance $\left(\mathrm{Cl}_{\text {int }}\right)$ of xenobiotics in the discovery phase of drug development (Smith et al. 2008). The generated in vitro $\mathrm{Cl}_{\text {int }}$ values are often extrapolated to in vivo using scaling factors such as the hepatocellularity number per gram of liver (HPGL) and the hepatic microsomal protein per gram of liver (MPPGL) (Hakooz et al. 2006). A relatively good correlation has been established between predicted and actual in vivo clearance in human and pre-clinical species (Riley et al. 2005). However, an important animal species that has been overlooked regarding in vitro-in vivo extrapolation (IVIVE) of drug clearance is the horse. Horses have both a commercial and a domestic role within society, ranging from companion animals to the equine sports and food industries. In all cases, the welfare of the horses must be considered, including appropriate medication when necessary. Furthermore, the equine sports industry which includes young, medium and older horses in flat racing, hurdles and Equestrian, respectively, is a multi-billion-dollar global business. Equine sports in addition to the food industry, require that any medications administered are at negligible concentrations at the time of competition or slaughter, respectively. The drug withdrawal time for negligible levels as well as the most appropriate dosing regimen will be dependent on the horse pharmacokinetics and therefore the ability to estimate drug clearance is paramount.

Microsomal scaling factors and hepatocellularity numbers for human, dog, rabbit, rat and mouse have been estimated using methodologies such as DNA, CYP and protein content (Carlile et al. 1997; Sohlenius-Sternbeck, 2006; Smith et al. 2008). However, horse MPPGL and HPGL have not been investigated.

The IVIVE of hepatic metabolic drug clearance has been mainly based on mean MPPGL and HPGL values for a given species with no estimate of intersubjective variability (Barter at al. 2007). Furthermore, a recent study found that there was up to 19 -fold individual variation in 
values of MPPGL in 128 human livers (Zhang et al., 2015). In this context, many reports have demonstrated specific age-dependent changes in some hepatic parameters, such as decreased protein and bile salt synthesis, and cholesterol metabolism (Tietz et al. 1992; Bertolotti et al. 1993; Schmucker 2005). Moreover, a number of studies have found strong negative correlations between age and hepatic microsomal Phase I drug-metabolising activity in inbred male rats (Schmucker \& Wang 1980; Schmucker \& Wang 1981; Schmucker \& Wang 1983; Yun et al. 2010). However, the results of studies conducted on non-human primates contradict the findings in rat as there was no apparent correlation between age-related changes in the microsomes and the in vitro activities of the constituent drug-metabolizing enzymes. (Maloney et al. 1986; Schmucker \& Wang 1987).

Several morphological studies have been conducted to study the effect of aging on liver structure (Tauchi 1961; Tauchi \& Sato 1962; de al Iglesia et al. 1976; Watanabe \& Tanaka 1982). The liver cell density of the inbred rat strain Fisher 344 increased between 1 and 16 month of age and, subsequently, declined such that the size of cells in immature and senescent animals was equivalent (Schmucker et al. 1978). Other changes in hepatocellular structure have been associated with advanced age, which include reduction in the surface area of the smooth surfaced endoplasmic reticulum, an increase in the volume of the mitochondrial and microbody compartments and an increase in hepatocyte polyploidy. Although none of these age-related changes manifest in a significant decline in hepatic function, there are data showing specific age related changes, such as a loss of liver size and a drop in liver perfusion (Schmucker et al. 1977; Schmucker et al., 1978; Watanabe \& Tanaka, 1982); both of which may affect certain hepatic functions, including first pass pharmacokinetics (Marchesini et al. 1988; Wynne et al. 1989).

In order to predict extreme effects in populations and to evaluate risk in horses with different age groups such variability should be assessed. Accordingly, the main aim of this study was to 
determine levels of MPPGL and HPGL as well as the effect of age on these levels and histology morphology in equine liver. 


\section{Materials and Methods}

Chemicals. Hank's buffered salt solution (HBSS) 10×, without calcium, magnesium or phenol red, Collagenase type IV and William's E Medium, no phenol red were purchased from Fisher Scientific (Loughborough, UK), Sodium dithionite (Sigma, UK). All other chemicals and reagents were commercial products of analytical grade.

\section{Source of liver samples.}

Liver samples were collected post slaughter from 39 horses (1-29 years old, the corresponding sex of the donor horses was not available) (Supplementary Table S1), slaughtered in accordance with the Welfare of Animals at the Time of Killing (UK) Regulations 2015. For microsome preparation, liver samples were flash frozen using dry ice. For hepatocyte preparation, liver samples were excised by a single transverse cut, and immediately after excising, immersed in $\operatorname{HBSS}\left(0-2^{\circ} \mathrm{C}\right)$ prior to being transported to the laboratory.

Histological study. Tissue fragments, obtained from 9 horses aged 1, 3, 5, 10, 16, 19, 21, 23 and 29 years-old, were fixed in $10 \%$ formalin for 24 hours at $4{ }^{\circ} \mathrm{C}$. After fixation, samples were processed using routine methods and embedded in paraffin wax. Sections were cut at $5 \mu \mathrm{m}$ thickness and stained with haematoxylin eosin $(\mathrm{H} \& \mathrm{E})$. To avoid any biased interpretation each slide was assigned a random number and the investigator was blinded to the identity of the sample. Three non-overlapping slides per horse were photographed in triplicate using 400x magnification (DM5000B, Leica, Germany). The number and size of hepatocytes in a chosen area were counted and measured using Image-Pro® plus Software, Media Cypernetics, USA. For hepatocyte size, the area of 35 cells/image were measured. The mean $\pm \mathrm{SD}$ was calculated using Microsoft Excel (Microsoft Excel 2010, Microsoft Corporation, USA). 
Homogenization of liver samples. Tissue samples (approximately $5 \mathrm{~g}$ ), previously stored at $80^{\circ} \mathrm{C}$, were thawed on ice and weighed accurately. The samples were finally chopped and homogenized using a blender for 60s in $0.15 \mathrm{M}$ potassium chloride buffer $\mathrm{pH} 7.4$ (10 ml/gram of liver). To discard any connective tissue, the homogenised samples were filtered through a nylon mesh (pore size $250 \mu \mathrm{m}$ ) (Fisher scientific, Loughborough, UK).

Preparation of microsomes. Microsomes were prepared according to a protocol described by Wilson et al. (2003). Briefly, the homogenates were centrifuged at 10,000g for 20 minutes at approximately $4^{\circ} \mathrm{C}$ and the supernatant (S24 fraction) retained. The supernatant was then centrifuged at 100,000g for 60 minutes and the resulting supernatant was discarded and the pellet re-suspended in ice cold 0.1 M phosphate buffered saline (PBS), before being centrifuged at $100,000 \mathrm{~g}$ for a further 60 minutes. The final pellet was then re-suspended in a volume of PBS equivalent to two thirds the weight of the original tissue. Samples of all fractions were stored at $-80{ }^{\circ} \mathrm{C}$ pending CYP450 and total protein determination.

Hepatocyte preparation. Hepatocytes were isolated by a two-step collagenase perfusion as described by Bakala et al. (2003). In brief, the liver was perfused at $37^{\circ} \mathrm{C}$ with a calcium-free HBSS ( $\mathrm{pH}$ 7.2) containing $0.1 \mathrm{mM}$ EGTA, followed by perfusion with HBSS containing collagenase type IV (1 mg/ml). After their release from the liver, hepatocytes were suspended in buffer containing Bovine Serum Albumin, filtered, washed twice by centrifugation, and resuspended in Williams E medium. The total number of cells (viable and nonviable cells) in each suspension were counted using the Trypan blue exclusion method (Tennant, 1964).

Homogenization of hepatocyte suspensions. Fresh hepatocyte suspensions of known cell concentration were cryopreserved as previously described (Shibany et al. 2016). Cryopreserved hepatocytes were thawed and the total number of cells was recounted. Suspensions were 
homogenized by freezing/thawing cycles. Homogenates were then assayed for CYP P450 content.

Protein determination. The total concentration of the protein of homogenate, microsomal samples and hepatocyte homogenates were measured according to Bradford (1976).

CYP P450 determination. A dithionite difference spectroscopy method (Matsubara et al. 1976) was used to determine the P450 content of the microsomes, hepatocytes and homogenate fractions using a UV4 UV/VIS spectrophotometer (Unicam, Cambridge, UK).

Values of MPPGL were calculated using the following equation: MPPGL $=(\mathrm{nmol}$ CYP

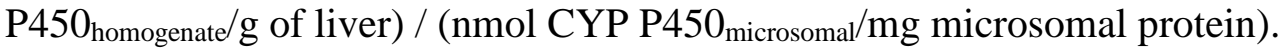

Correction for loss of microsomal protein. The fraction of microsomal protein lost during the microsomal preparation process was determined. Since microsomes contain over $96 \%$ of the CYP P450 content of the liver, the total CYP P450 contents of homogenate and microsomal samples were measured and used to determine the correction factors (Wilson et al., 2003).

\section{Determination of Hepatocellularity.}

CYP P450 content method: The CYP P450 content of whole liver homogenates and homogenates of hepatocyte suspensions from 18 equine livers were determined by dithionite difference spectrometry. The following equation was then used to calculate HPGL values: Number of hepatocytes per gram of liver $=\left(\right.$ nmol CYP P450 ${ }_{\text {homogenate }} / \mathrm{g}$ of liver $) /(\mathrm{nmol}$ CYP P450 hepatocytes $/ 10^{6}$ cells) (Wilson et al. 2003).

Protein method: $97 \%$ of liver protein is contained in hepatocytes, and in a suspension of isolated hepatocytes this value is $99 \%$ (Worboys et al., 1996). Hence the hepatocellularity can be calculated from the ratio between the liver protein concentration and the protein concentration in the corresponding hepatocyte suspension, corrected by $0.97 / 0.99$. 


\section{Statistical analysis}

All data are presented as means \pm standard deviations of the number of samples used. Significant differences between groups were determined using an analysis of variance (ANOVA) followed by the Tukey multiple range test $(\mathrm{P}<0.05)$. Significance of any linear correlations was analysed using the regression slope statistics. All statistics were carried out using GraphPad Prism version 6.0 (GraphPad Software Inc., San Diego, CA, USA). 


\section{Results}

For the 39 livers investigated, the total protein concentration of the liver homogenates and microsomes was $21.5 \pm 5 \mathrm{mg} / \mathrm{ml}$ and $31.1 \pm 6 \mathrm{mg} / \mathrm{ml}$, respectively. The mean value for protein concentration for the isolated hepatocytes was $1.0 \pm 0.3 \mathrm{mg} / 10^{6}$ cells. The CYP P450 concentrations in liver homogenate, equine microsomes and hepatocytes were 29.6 \pm 6.6 , $0.510 \pm 0.09$ and $0.130 \pm 0.02 \mathrm{nmol} \mathrm{P} 450 / \mathrm{g}$ liver, respectively (Supplementary Table S2). The CYP P450 content of whole homogenate correlated with that of microsomes $\left(\mathrm{r}^{2}=0.533, p<\right.$ 0.0001) Supplementary Figure S1. The ratio of the whole homogenate CYP P450 content to the CYP P450 content for microsomes and hepatocytes provided scaling factors for each liver with an average of $57 \mathrm{mg}$ microsomal protein/g liver $(\mathrm{CV}=15 \%)$ and hepatocellularity of 227 $\mathrm{x} 10^{6}$ cells/g of liver $(\mathrm{CV}=26 \%)$, respectively (Table 1$)$. For the protein method, the mean hepatocellularity was $232 \times 10^{6}$ cells/ g liver $(\mathrm{CV}=21 \%)$. The operator had no significant influence on estimated values for MPPGL and HPGL as no correlation existed between measurements and time for a 21-month period $(p>0.05)$ Supplementary Figure S2.

Levels of hepatic total CYP P450 content per gram of liver increased significantly in the horses aged between 10 and 20-years-old relative to the $<10$ and $>20$-year-old horses (Figure 1A). On the other hand, the total CYP P450 content in equine liver microsomes per mg protein did not change significantly over the ages examined in this study (Figure 1B).

A U-shaped relationship was observed between CYP P450 content per $10^{6}$ hepatocytes and the horse age (Figure 1C). Furthermore, Figure 2A shows a non-monotonic relationship between age and MPPGL with values increasing from $41 \mathrm{mg} / \mathrm{g}$ of liver (5-year-old) to a maximum of $73 \mathrm{mg} / \mathrm{g}$ of liver (17-year-old) followed by a gradual decrease in older age. This gradual decrease was not statistically significant, however, the increase in MPPGL in horses aged 1020 years old compared to 0-9 years old was significant. Hepatocellularity increased gradually with age to reach the maximum level at 19 years old. Subsequently, the cell number declined 
until the hepatocytes of the oldest horses almost approached the number of those found in the youngest horses (Figure 2B). HPGL was significantly higher in horses between 10 and 20years-old compared to that in horses $<10$ and $>20$ years-old.

Hepatocellularity determined using the protein method showed a similar pattern to the results obtained from the CYP P450 method (Supplementary Figure S3).

There was an inverse relationship between HPGL and CYP P450 content per $10^{6}$ hepatocytes, i.e. the lower the HPGL the higher the CYP P450 content per $10^{6}$ cells (Figure 3).

Age-related alterations in the size and number of equine hepatocytes were studied in histological sections of liver samples obtained from 9 horses. The cell size and number per unit area (mean \pm SD) of hepatocytes for each age category is summarised in Table 2. Between 1 and 20 years of age the cell size of equine hepatocytes decreased in size as age increased. Subsequently, the cell size increased until the hepatocytes of the oldest horses approached the size of those found in the youngest animals. Horses between 10 and 20-years-old contained significantly smaller hepatocytes than horses older than 21-years-old (Figure 4A). The number of hepatocytes per unit area increased and decreased inversely with the changes in hepatocyte size over age. There was a significant difference in the number of cells per unit area between 10 and 20 years and $<10$ and $>20$-year-old horses (Figure 4B).

The HPGL was highly correlated with the number of cells per unit area $\left(\mathrm{r}^{2}=0.8294, \mathrm{P}<0.05\right)$ and cell size $\left(\mathrm{r}^{2}=0.7323, \mathrm{P}<0.05\right)$ shown in Figures $5 \mathrm{~A}$ and $5 \mathrm{~B}$, respectively. 


\section{Discussion}

Microsomal protein per gram of liver (MPPGL) and hepatocellularity (HPGL) are used frequently as scaling factors to predict the in vivo hepatic metabolic clearance of a xenobiotic for human (Houston, 1994). However, there is no information about these scaling factors for horses reported in the literature. In the present study, the MPPGL and HPGL for horse were determined from CYP P450 and protein measurements.

The CYP P450 content in equine liver microsomes was almost double compared to human; in contrast, there was no difference in CYP P450 content in hepatocytes, between horse and human (Supplementary Table S2). The mean value for horse microsomal protein was 57 (4173) $\mathrm{mg} / \mathrm{g}$ of liver, and there was no difference in HPGL between the two methods used; CYP P450 content method $227(146-320) \times 10^{6}$ cells/g of liver and protein method $232(156-352) \times$ $10^{6}$ cells/g of liver. The hepatocellularity number obtained for the horse is higher than other species. One possible explanation for this may be due to the diameter of horse hepatocytes $(14.6 \pm 4.8 \mu \mathrm{m})$ being smaller than the diameter of hepatocytes from other species; $19.2 \pm 0.6 \mu \mathrm{m}$ in rat, $18.4 \pm 0.8 \mu \mathrm{m}$ in pigs, and between $20-30 \mu \mathrm{m}$ in human (Engelmann et al. 1981; Stegemann et al. 2000; Boyer et al., 2017). On the other hand, the microsomal protein value obtained from the horse was similar to values obtained for dog and rat; however, it was higher than that obtained for human (Table 1). Furthermore, there is a statistically significant nonmonotonic relationship between age and both MPPGL and HPGL in horses.

These findings are consistent with the literature for other species; Basu et al. (1971) studied the effect of the activity of microsomal drug metabolising enzymes with age in rat liver and found that the total microsomal protein increased progressively until the age of 70 days and thereafter it remained more or less constant. Moreover, a study which collated and analysed data from a number of sources found that there was a weak but statistically significant inverse relationship between age and both MPPGL and HPGL in human (Barter et al. 2007). Similarly, Barter et 
al. (2008) found that values of MPPGL were approximately 36 and 31\% lower in new born and elderly (80 years old) individuals than those in a 25 -year-old individual. However, recently Zhang et al. (2015), suggested that the variation in content and activity of human liver microsomal protein was due to individual variations rather than an age-dependent variation. The micrometric measurements of hepatocytes in histological specimens, in the present study, revealed that very young and aged horses possess fewer but larger hepatocytes than middle age horses. Moreover, there is an inverse relationship between size and number of hepatocytes in a unit area. These findings are in agreement with those reported in the literature; Tauchi (1961) reported that the number of cells in human and rat liver samples decreased to a certain degree with advanced age while hepatocyte size increased. Furthermore, the fall in hepatocyte number with advancing age has been observed in human liver (Wakabayashi et al. 2002).

The increase in hepatocyte size in young subjects may be due to the fast growth demands in this period of age which allows the liver to adapt with a high-energy demand (De la Iglesia et al. 1976). On the other hand, the increase in hepatocyte size in aged subjects may be due to nuclear polyploidisation rather than compensatory hypertrophy (Tauch \& Sato 1962; Watanabe \& Tanaka 1982).

While it has been shown that there is a statistically significant inverse relationship between age and CYP P450 content/mg microsomes in female horses (Nebbia et al., 2004), the present study found that age has no effect on CYP P450 content/mg microsomes. However, the effect of sex could not be studied in the present study due to lack of information regarding the corresponding sex of donor horses. The results of the present study suggest that the increase of MPPGL was due to the increase in the total number of hepatocytes per gram of liver rather than an increase in the expression of CYP P450 resulting from an increase in smooth endoplasmic reticulum (SER) surface area. This cell-size dependent difference in MPPGL content has been reported in human hepatocytes (De la Iglesia et al., 1975). This has been confirmed in the herein study 
by the presence of a significant inverse relationship between CYP P450 per $10^{6}$ cells and HPGL which may help horses with low HPGL to maintain their xenobiotic metabolic capacity by having higher levels of CYP P450 per hepatocyte. This observation has also been reported in human hepatocytes (Wilson et al., 2003).

There are a number of limitations to the present study. Firstly, the corresponding sex of the donor horses was not available, hence it was not possible to study the effect of gender on the CYP P450 content, MPPGL and hepatocellularity number. Secondly, all liver samples used in this study were frozen. A number of studies have found that the freezing of liver samples may have a negative effect on the stability of CYP P450. Smith et al. (2008) found that the mean rat and dog CYP P450 content determined from frozen homogenate was almost half of the P450 content of fresh homogenate. However, the activity of CYP P450 in homogenate prepared from fresh and frozen rat liver tissue was assessed using several known P450 substrates, and the results showed that the intrinsic P450 enzyme activity was unaffected by freezing the homogenate. Hence, calculation of microsomal scaling factors should not be affected by the freezing of liver samples (Smith et al., 2008).

Furthermore, a study that was conducted to examine the stability of CYP P450 in frozen human microsomes found that the concentration of CYP P450 decreased by 20-40\% (Pearce et al. 1996). However, freezing human liver tissue had no effect on the stability of CYP P450 which suggests it does not convert to its inactive P420 form, but the accuracy of the P450 assay may have been affected due to contamination of liver tissue fractions with haemoglobin and other haem-containing proteins (Pearce et al., 1996).

The values of MPPGL and HPGL determined for horse in the present study can be used to scale up the in vitro intrinsic clearance $\left(\mathrm{Cl}_{\text {int }}\right)$ of a drug, measured in microsomes or hepatocytes, to the liver metabolic intrinsic clearance (Iwatsubo et al., 1997). This scaled value can then be used to estimate the hepatic metabolic clearance in horse using models such as the 
well stirred or parallel tube model. However, this requires a knowledge of hepatic blood flow and the plasma free fraction of drug in horse. Furthermore, the scaling factors determined in this study can be used in conjunction with data from other species to perform interspecies allometric scaling (Mahmood, 2007). In this context, Lave et al. (1996) successfully predicted bosentan clearance in human by combining data obtained from in vitro liver systems i.e. hepatocytes and microsomes, with the in vivo clearances in animals. Therefore, interspecies allometric scaling of animal clearance values, corrected for liver metabolic intrinsic clearance estimated using the herein in vitro scaling factors, may improve predictions of hepatic metabolic clearance in the horse. Alternatively, interspecies allometric scaling for drug clearance, that includes horse, can be corrected for liver metabolic intrinsic clearance obtained from human in vitro studies in order to predict human hepatic metabolic clearance. The addition of horse as a species would mean that the human prediction results from allometric interpolation rather than extrapolation as the horse has a larger body weight.

In conclusion, this study has established values for equine liver microsomal and hepatocyte number scaling factors of $57 \mathrm{mg}$ microsomal protein per gram liver and $227 \times 10^{6}$ per gram liver, respectively. This is the first time that these scaling factors have been determined for the horse. Furthermore, the influence of age was investigated, and the results suggest that MPPGL and HPGL values are dependent on the age of the horse and corrections should be made when predictions of hepatic clearance for xenobiotics are carried out using in vitro-in vivo extrapolation.

Finally, further investigation is needed with regard to the effect of horse gender and breed on MPPGL and HPGL. 


\section{Acknowledgments}

Funding was provided by the Ministry of Higher Education and Scientific Research-Libya and in part by The Welcome Trust [Grant number 109186/Z/15/Z]. The content is solely the responsibility of the authors and does not necessarily represent the views of Ministry of Higher Education and Scientific Research-Libya and The Welcome Trust.

We thank Mr. Wayne Sanders for his help in sample collection, Prof. Andrew Salter and Mr. Michael Garle for their help in microsomes preparation and CYP P450 measurements.

\section{Disclosure of Interest}

The authors declare there is no conflict of interests other than the research has been part funded by The Wellcome Trust [Grant number 109186/Z/15/Z].

\section{Authorship Contributions:}

Participated in research design: K.A. Shibany, S. Tötemeyer, S.L. Pratt, S.W. Paine

Conducted experiments: K.A. Shibany and S.L. Pratt

Performed data analysis: K.A. Shibany and S.L. Pratt

Contributed to writing manuscript: K.A. Shibany, S. Tötemeyer, S.L. Pratt, S.W. Paine 


\section{References}

Bakala, A., Karlik, W. and Wiechetek, M. (2003). Preparation of equine isolated hepatocytes. Toxicology in Vitro, 17(5-6), 615-621.

Barter, Z., Bayliss, M., Beaune, P., Boobis, A., Carlile, D., Edwards, R., Houston J.B., Lake B.G., Lipscomb J.C., Pelkonen O.R., Tucker G.T., Rostami-Hodjegan A. (2007). Scaling Factors for the Extrapolation of In Vivo Metabolic Drug Clearance From In Vitro Data: Reaching a Consensus on Values of Human Micro-somal Protein and Hepatocellularity Per Gram of Liver. Current Drug Metabolism, 8(1), 33-45.

Barter, Z. E., Chowdry, J. E., Harlow, J. R., Sanwder, J. E. and Lipscomb, J. C. (2008). Covariation of Human Microsomal Protein Per Gram of Liver with Age : Absence of Influence of Operator and Sample. Drug Metabolism and Disposition, 36(12), 24052409.

Basu, T. K., Dickerson, J. W. T. and Parke, D. V. W. (1971). Effect of Development on the activity of Microsomal Drug-Metabolizing Enzymes in Rat Liver. Biochem. J., 124, 1924.

Bertolotti, M., Abate, N., Bertolotti, S., Loria, P., Concari, M., Messora, R., Carubbi F., Pinetti A., Carulli N. (1993). Effect of aging on cholesterol 7a-hydroxylation in humans. J. of Lipid Res., 34, 1001-1007.

Boyer, T. D., Sanyal, A. J., Lindor, K. D. and Terrault, N. A. (2018). Zakim and Boyer's Hepatology: A Textbook of Liver Disease. (A. J. Sanyal, K. D. Lindor, T. D. Boyer, and N. A. Terrault, Eds.) (7th ed.). Philadelphia: Elsevier.

Bradford, M. M. (1976). A rapid and sensitive method for the quantitation of microgram quantities of protein utilizing the principle of protein-dye binding. Analytical Biochemistry, 72, 248-54. 
Carlile, D. J., Zomorodi, K. and Houston, J. B. (1997). Scaling Factors to Relate Drug Metabolic Clearance in Hepatic Microsomes, Isolated Hepatocytes, and the Intact Liver, Drug Metabolism and Disposition. 25(8), 903-911.

De al Iglesia, F. A., Sturgess, J. M., McGuire, E. J. and Feuer, G. (1976). Quantitative Microscopic Evaluation of the Endoplasmic Reticulum in Developing Human Liver. American Journal of Pathology, 82(1), 61-70.

Engelmann, G. L., Richardson, A., Katz, A. and Fierer, J. A. (1981). Age-Related Changes in Isolated Rat Hepatocytes. Compansation of Size, Morphology, Binucleation, and Protein Content. Mechanisms of Aging and Development, 16, 385-395.

Hakooz, N., Ito, K., Rawden, H., Gill, H., Lemmers, L., Boobies, A. R., Edwards R.J., Carlile D.J., Lake B.G., Houston J.B. (2006). Determination of a Human Hepatic Microsomal Scaling Factor for Predicting in vivo Drug Clearance. Pharmaceutical Research, 23, $533-539$.

Houston, J. B. (1994). Utility of In Vitro Drug Metabolism Data in Predicting In vivo Metabolic Clearance. Biochemical Pharmacology, 47(9), 1469-1479.

Iwatsubo, T., Hirota, N., Ooie, T., Suzuki, H., Shimada, N., Chiba, K. and Sugiyama, Y. (1997). Prediction of In Vivo Drug Metabolism in the Human Liver from In Vitro Metabolism Data. Pharmacology \& Therapeutics, 73(2), 147-171.

Lave, T., Coassolo, P., Ubeaud, G., Brandt, R., Schmitt, C., Dupin, S. and Chou, R. C. (1996). Interspecies scaling of bosentan, a new endothelin receptor antagonist and integration of in vitro data into allometric scaling. Pharmaceutical Research, 13(1), 97101.

Mahmood, I. (2007). Application of allometric principles for the prediction of pharmacokinetics in human and veterinary drug development. Advanced Drug Delivery 
Reviews, 59(11), 1177-1192.

Maloney, A. G., Schmucker, D. L., Vessay, D. S. and Wang, R. K. (1986). The Effects of Aging on the Hepatic Microsomal Mixed- Function Oxidase System of Male and Female Monkeys. Hepatology, 6(2), 282-287.

Marchesini, G., Bua, V., Brunori, A., Bianchi, G., Pisi, P., Fabbri, A., Zoli M., Pisi E. (1988). Galactose elimination capacity and liver volume in aging man. Hepatology, 8(5), 1079-83.

Nebbia, C., Dacasto, M. and Carletti, M. (2004). Postnatal development of hepatic oxidative, hydrolytic and conjugative drug-metabolizing enzymes in female horses. Life Sciences, 74(13), 1605-1619.

Pearce, R. E., Mcintyre, C. J., Madan, A., Sanzgiri, U., Draper, A. J., Bullock, Cook D.C., Burton L.A., Latham J., Nevins C., Parkinson A. (1996). Effects of Freezing, Thawing, and Storing Human Liver Microsomes on Cytochrome P450 Activity. Archives of Biochemistry and Biophysics, 331(2), 145-169.

Riley, R. J., Mcginnity, D. F. and Austin, R. P. (2005). A Unified Model for Predicting Human Hepatic, Metabolic Clearance from In Vitro Intrinsic Cearance Data in Hepatocytes and Microsomes. Pharmacology, 33(9), 1304-1311.

Schmucker, D. L. (2005). Age-related changes in liver structure and function: Implications for disease? Experimental Gerontology, 40(8-9), 650-659.

Schmucker, D. L., Mooney, J. S. and Jones, A. L. (1978). Stereological analysis of hepatic fine structure in the Fischer 344 rat. Influence of sublobular location and animal age. Journal of Cell Biology, 78(2), 319-337.

Schmucker, D. L. and Wang, R. K. (1980). Effects of Animal Age and Phenobarbital on Rat Liver Glucose-6-Phospahte activity. Experimental Gerontology, 15, 249-261. 
Schmucker, D. L and Wang, R. K. (1981). Effect of Aging and Phenobarbital on the Rat Liver Microsomal Drug-Metabolizing system. Aging Dev, 4, 81-92.

Schmucker, D. L. and Wang, R. K. (1983). Age-dependent alteration in Rat Liver Microsomal NADPH Cytochrome c (P-450) Reductase: a Qualitative and Quantitative analysis. Aging Dev, 21, 137-156.

Schmucker, D. L. and Wang, R. K. (1987). Effects of aging on the properties of rhesus monkey liver microsomal NADPH-cytochrome c (P-450) reductase. Drug Metabolism and Disposition, 15, 225-232.

Schmucker, L. D., Mooney, J. S. and Albert, J. L. (1977). Age-Related Changes in the Hepatic Endoplasmic Reticulum: A Quantitive Analysis. Science, 197, 1005-1008.

Shibany, K. A., Tötemeyer, S., Pratt, S. L., \& Paine, S. W. (2016). Equine hepatocytes: isolation, cryopreservation, and applications to in vitro drug metabolism studies. Pharmacology Research \& Perspectives, 4(5), 1-8.

Smith, R., Jones, R. D. O., Ballard, P. G. and Graffiths, H. H. (2008). Determination of microsome and hepatocyte scaling factors for in vitro/in vivo extrapolation in the rat and dog. Xenobiotics, 38(11), 1386-1398.

Sohlenius-Sternbeck, A.-K. (2006). Determination of the hepatocellularity number for human, dog, rabbit, rat and mouse livers from protein concentration measurements. Toxicology in Vitro, 20(8), 1582-1586.

Stegemann, J. P., Raina, S., Nicholson, D. T., Jimenez, P., Shah, L., Cain, S., Chandler B., Pitkin Z., Mullon C., Custer L. (2000). Comparison of analytical methods for quantitation of isolated porcine hepatocyte yields. Tissue Engineering, 6(3), 253-64.

Tauchi, H. (1961). On the fundamental morphology of the senile changes. Nagoya Journal of Medical Science, 24, 97-132. 
Tauchi, H. and Sato, T. (1962). Some Micromeasuring Studies of Hepatic Cells. Journal of Gerontology, 17(3), 254-259.

Tennant, J. R. (1964). Evaluation of the Trypan Blue Technique for Determination of Cell Viability. Transplantation, 2(6), 685-693.

Tietz, N. W., Shuey, D. F. and Wekstein, D. R. (1992). Laboratory values in fit aging individuals - Sexagenarians through centenarians. Clinical Chemistry, 38(6), 11671185.

Wakabayashi, H., Nishiyama, Y., Ushiyama, T., Maeba, T. and Maeta, H. (2002). Evaluation of the effect of age on functioning hepatocyte mass and liver blood flow using liver scintigraphy in preoperative estimations for surgical patients: comparison with CT volumetry. The Journal of Surgical Research, 106(2), 246-253.

Watanabe, T. and Tanaka, Y. (1982). Age-Related Alterations in the Size of Human Hepatocytes. Virchows Archive B, 39, 9-20.

Wilson, Z. E., Rostami-Hodjegan, a, Burn, J. L., Tooley, a, Boyle, J., Ellis, S. W. and Tucker, G. T. (2003). Inter-individual variability in levels of human microsomal protein and hepatocellularity per gram of liver. British Journal of Clinical Pharmacology, 56(4), 433-40.

Worboys, P. D., Bradbury, A. and Houston, J. B. (1996). Kinetics of drug metabolism in rat liver slices. II. Comparison of clearance by liver slices and freshly isolated hepatocytes. Drug Metabolism and Disposition, 24, 676-681.

Wynne, H. A., Cope, L. H., Mutch, E., Rawlins, M. D., Woodhouse, K. W. and James, O. F. W. (1989). The effect of age upon liver volume and apparent liver blood flow in healthy man. Hepatology, 9(2), 297-301.

Yun, K. U., Oh, S. J., Oh, J. M., Kang, K. W., Myung, C.-S., Song, G. Y., ... Kim, S. K. 
(2010). Age-related changes in hepatic expression and activity of cytochrome P450 in male rats. Archives of Toxicology, 84(12), 939-46. https://doi.org/10.1007/s00204-0100520-1

Zhang, H., Gao, N., Tian, X., Liu, T., Fang, Y., Zhou, J., Wen Q., Xu B., Qi B., Gao J., Li H., Jia L., Qiao H. (2015). Content and activity of human liver microsomal protein and prediction of individual hepatic clearance in vivo. Scientific Reports, 5, 1-12. 


\section{TABLE 1}

Calculated horse data compared with other species. Source (Sternbeck, 2006; Barter et al. 2007; Smith et al. 2008)

\begin{tabular}{lccc}
\hline Species & $\begin{array}{c}\text { Microsomal protein } \\
\text { (mg protein/ g liver) }\end{array}$ & Hepatocellularity (cells $\times \mathbf{1 0 6} / \mathbf{g}$ & *Hepatocellularity $($ cells $\times \mathbf{1 0 6 /}$ \\
\hline Human & $32(29-34)$ & liver $)$ & g liver) \\
Dog & $55(48-62)$ & $169(131-207)$ & $139 \pm 25$ \\
Rat & $61(47-75)$ & $163(127-199)$ & $117 \pm 30$ \\
Horse & $57(41-73)$ & $227(146-320)$ & $232 \pm 49$ \\
\hline
\end{tabular}

* hepatocellularity was determined using protein method 
TABLE 2

Hepatocyte size and number of cells per unit area at different ages

\begin{tabular}{|l|c|c|c|c|c|c|c|c|c|}
\hline & \multicolumn{3}{|c|}{ 0-9 years } & \multicolumn{3}{c|}{$10-20$ years } & \multicolumn{3}{c|}{$>20$ years } \\
\hline & 1 & 3 & 5 & 10 & 18 & 19 & 21 & 23 & 29 \\
\hline Cell size $\left(\mu^{2}\right)$ & 171.2 & 188.1 & 163.6 & 162.0 & 146.8 & 137.7 & 172.2 & 175.0 & 196.3 \\
& \pm 16.9 & \pm 22.3 & \pm 23.7 & \pm 12.4 & \pm 16.3 & \pm 15.0 & \pm 18.5 & \pm 24.4 & \pm 13.7 \\
\hline No of cells & 150.3 & 138.3 & 160 & 171.6 & 176 & 201 & 141.3 & 137 & 133 \\
& \pm 5.5 & \pm 6.7 & \pm 2.0 & \pm 14 & \pm 13 & \pm 12 & \pm 2.0 & \pm 4.0 & \pm 2.5 \\
\hline
\end{tabular}

Values expressed as mean $\pm S D$, measurements performed in triplicate for each animal 


\section{Legends for figures:}

Figure 1. Relation between horse age and nmol CYP P450/g of liver (A), nmol P540/mg of liver microsomal protein and horse age (B), CYP P450 content per $10^{6}$ hepatocytes $(C)(n=39)$. Comparisons of the three different age groups were made using a one-way ANOVA followed by Tukey's multiple comparison test (F). Each value represents the mean \pm SD for 7-16 horses. $*=\mathrm{P}<0.05$

Figure 2. Relation between horse age and MPPGL (n=39) (A), HPGL (n=18) (B). Comparisons of the three different age groups were made using a one-way ANOVA followed by Tukey's multiple comparison test $(\mathrm{B}) .{ }^{*}=\mathrm{P}<0.05$.

Figure 3. Correlation between HPGL and CYP P450 content per $10^{6}$ cells for 18 equine livers $\left(\mathrm{r}^{2}=0.3926, \mathrm{P}<0.05\right)$

Figure 4. Relation between age and size (A) and the number of hepatocytes per unit area (B) $(n=9)$. Comparisons of the three-different age groups were made using a one-way ANOVA followed by Tukey's multiple comparison test (B). Each value represents the mean \pm SD for 3 horses. $*=\mathrm{P}<0.05$.

Figure 5. Relationship between HPGL and number of cells (A) and cell size (B). There is a strong $\left(r^{2}=0.8294\right)$ and $\left(r^{2}=0.7323\right)$, statistically significant $(\mathrm{P}<0.05)$ relationship between these values, respectively. 
A
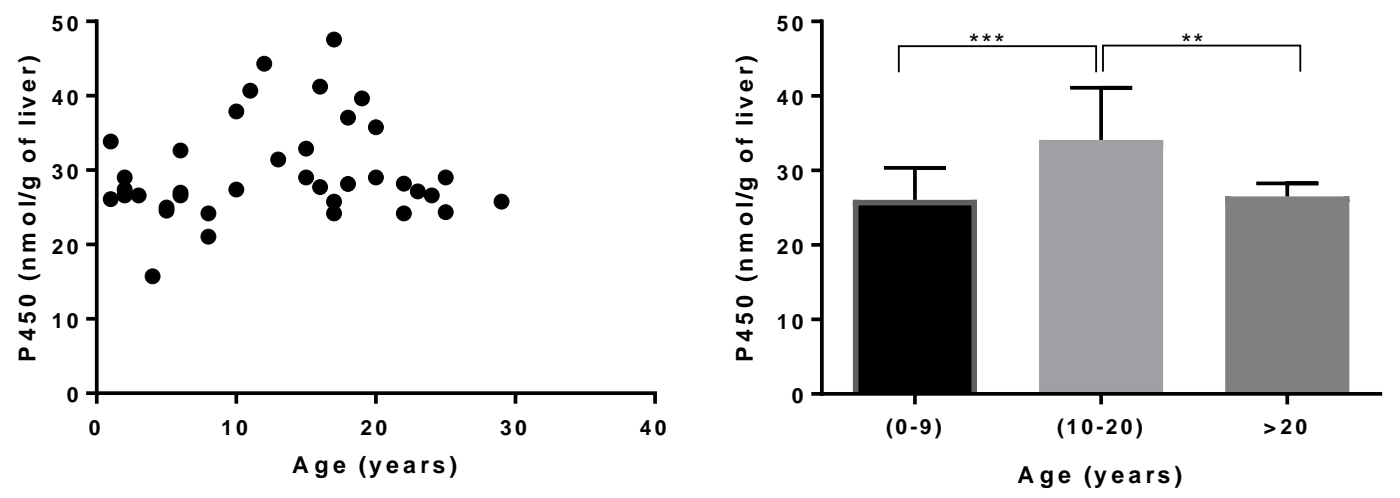

B
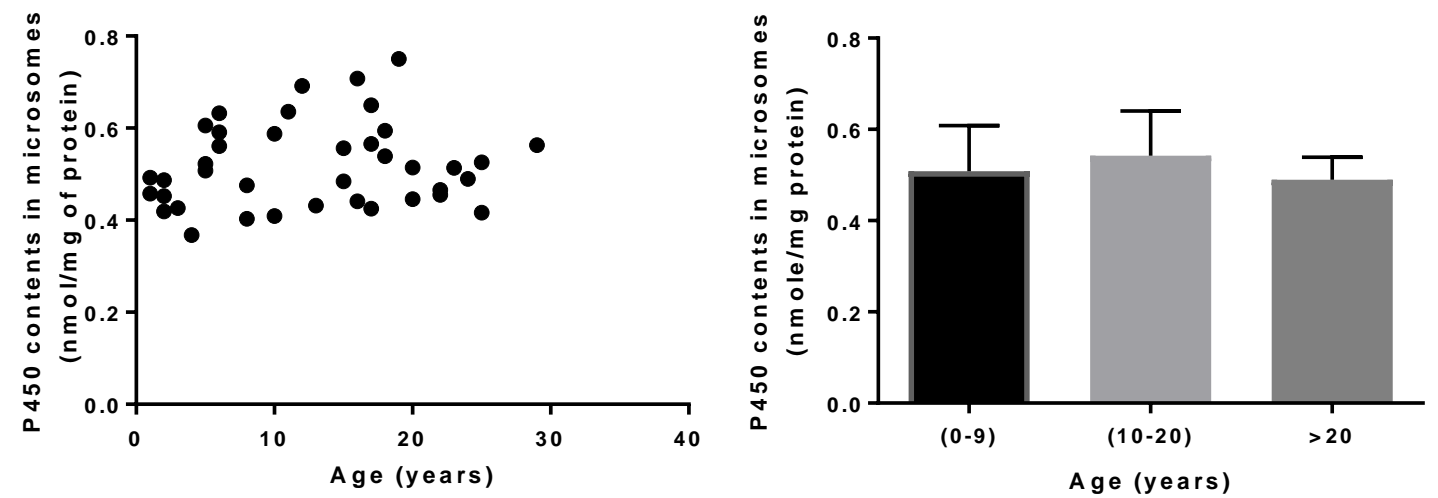

C
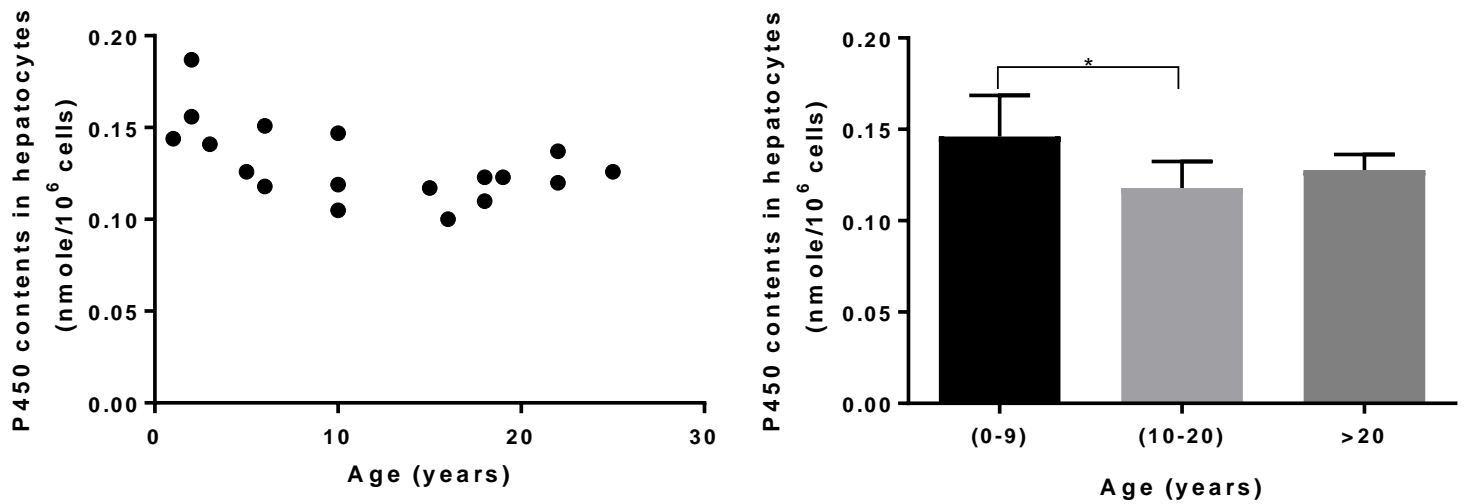

Figure 1 
A
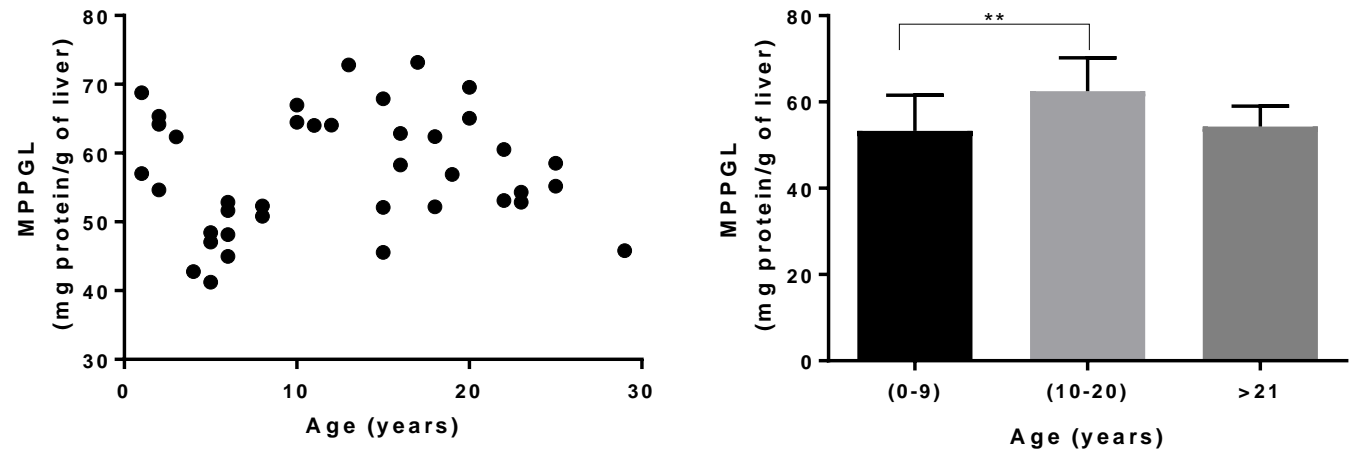

B
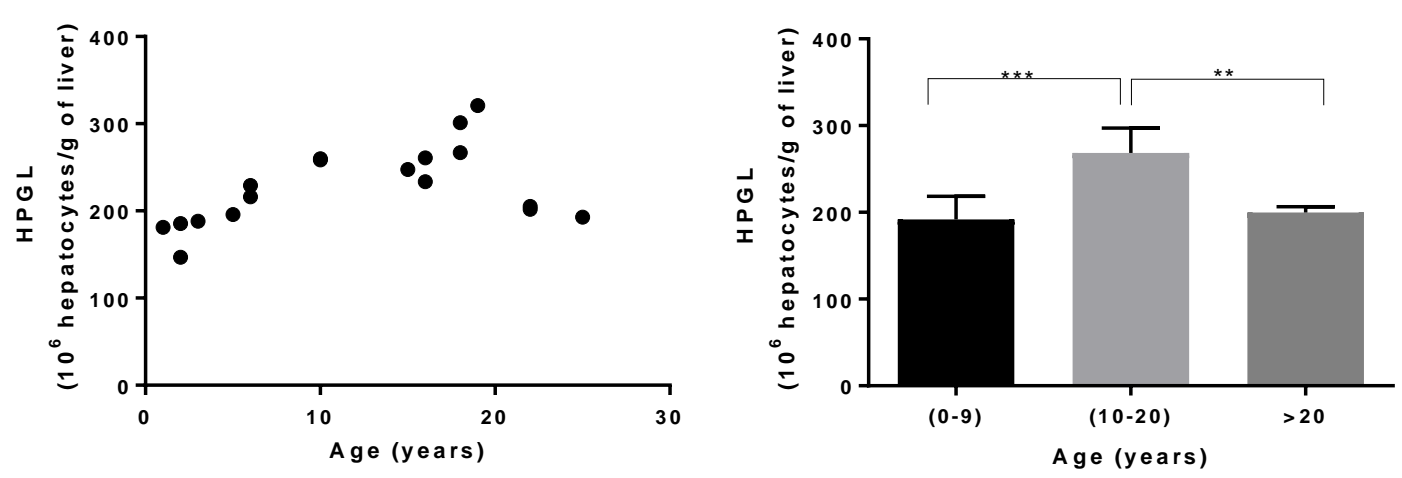

Figure 2 


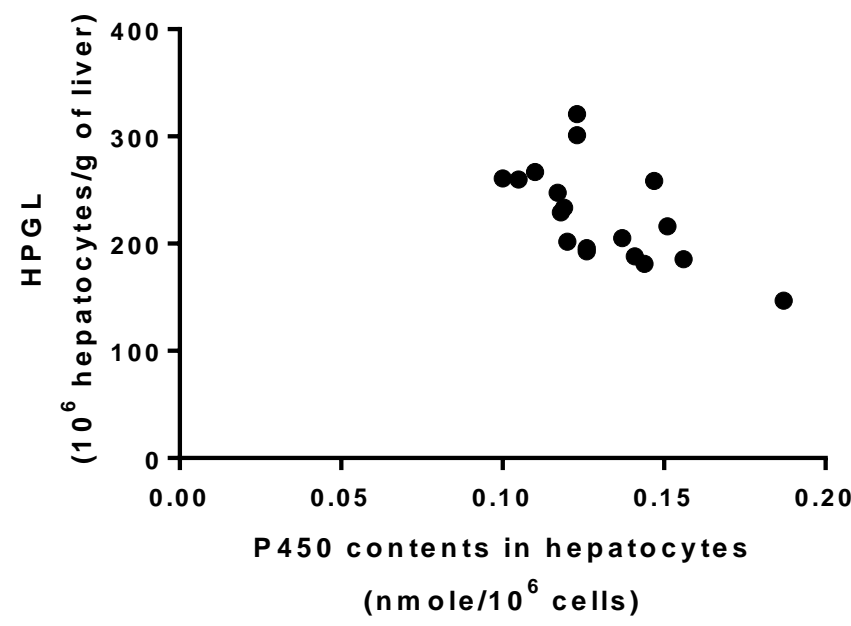

Figure 3 
A
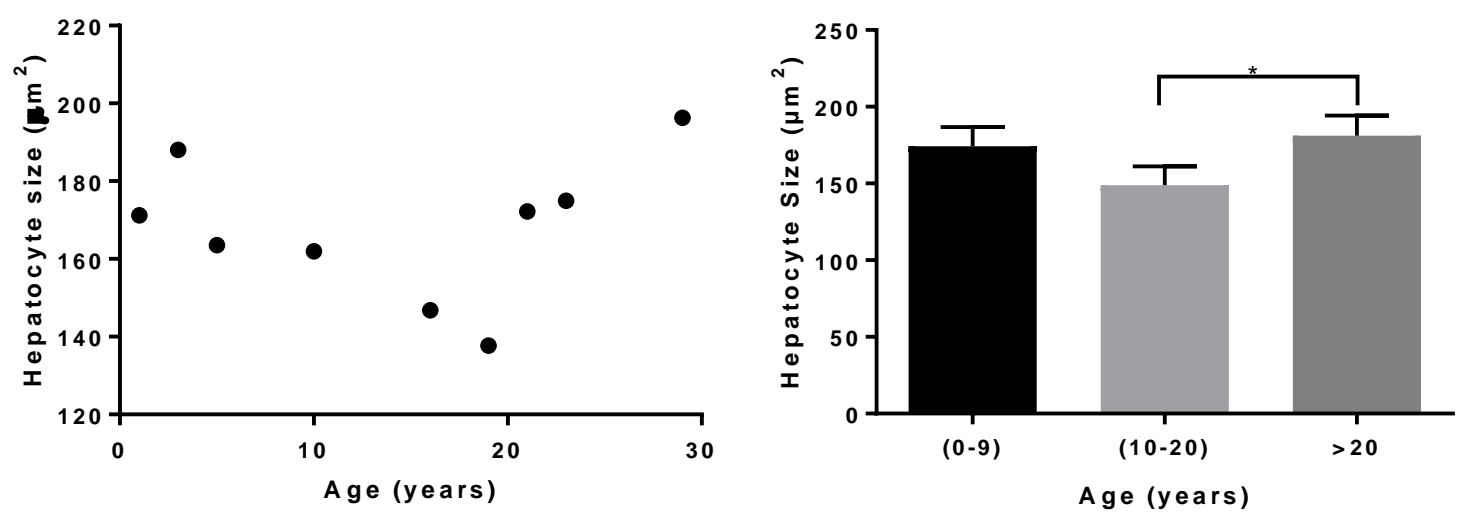

B
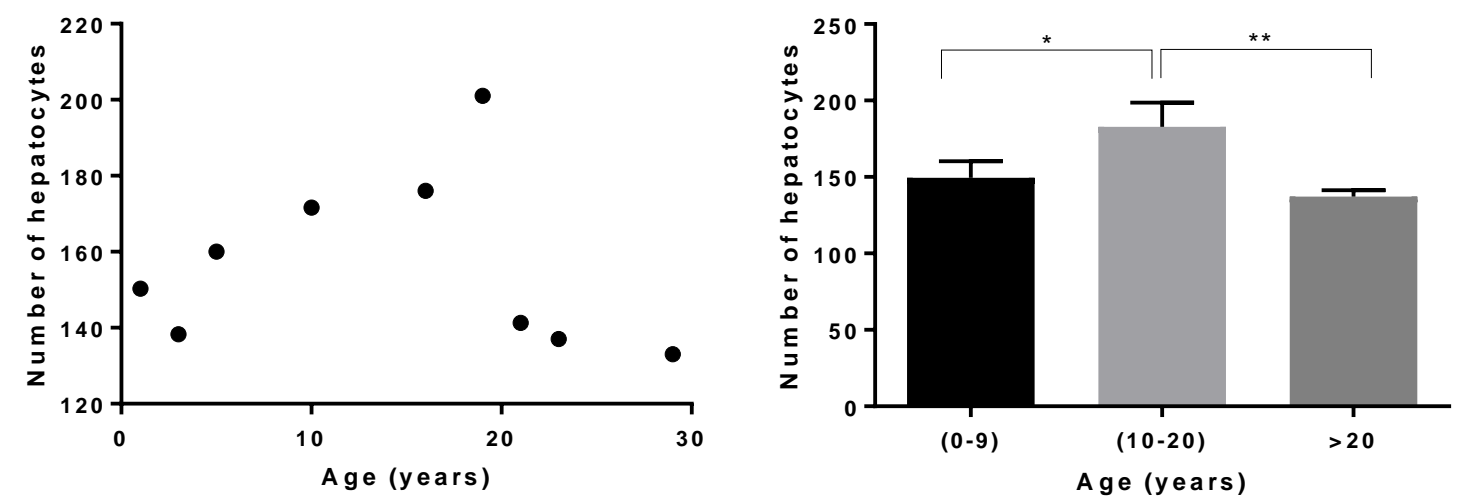

Figure 4 

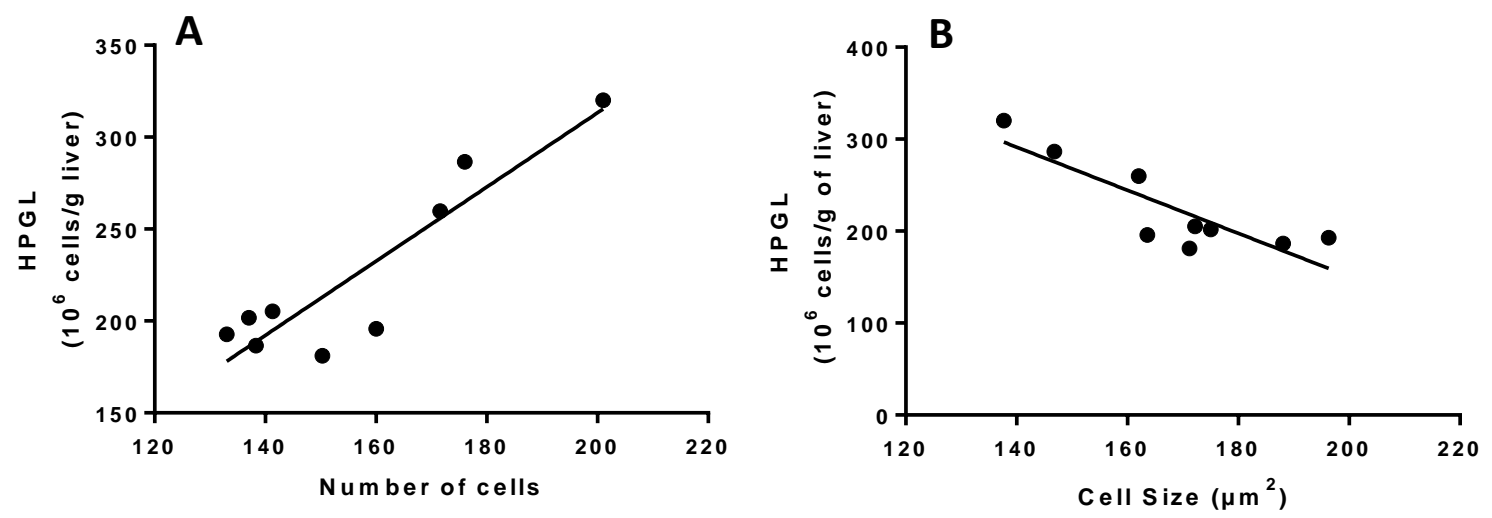

Figure 5 